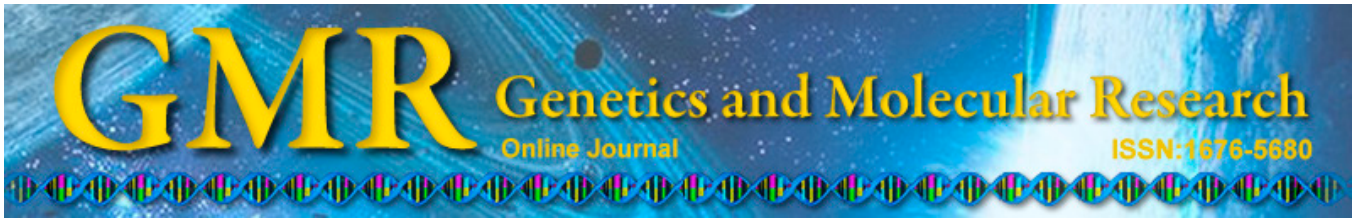

\title{
Novel polymorphic microsatellite markers isolated from the pen shell Atrina pectinata (Mollusca: Bivalvia: Pinnidae)
}

\author{
B. Wu ${ }^{1}$, L.J. Bai ${ }^{1,2}$,A.G. Yang ${ }^{1}$, L.Q. Zhou ${ }^{1}$ and Z.H. Liu ${ }^{1}$ \\ ${ }^{1}$ Key Laboratory of Sustainable Development of Marine Fisheries, \\ Ministry of Agriculture, Yellow Sea Fisheries Research Institute, \\ Chinese Academy of Fishery Sciences, Qingdao, China \\ ${ }^{2}$ College of Fisheries and Life Science, Shanghai Ocean University, \\ Shanghai, China
}

Corresponding author: A.G. Yang

E-mail: yangag@ysfri.ac.cn

Genet. Mol. Res. 13 (4): 10643-10647 (2014)

Received October 11, 2013

Accepted November 10, 2014

Published December 18, 2014

DOI http://dx.doi.org/10.4238/2014.December.18.6

\begin{abstract}
In this study, we isolated 21 novel polymorphic microsatellite DNA loci from the pen shell Atrina pectinata using magnetic-bead hybridization enrichment. The characteristics of these loci were tested using a population of 30 individuals collected from the Penglai coast, Shandong Province. The number of alleles ranged from 2 to 13, and polymorphism information content (PIC) varied from 0.1730 to 0.8954 . Values for observed heterozygosity $\left(H_{\mathrm{O}}\right)$ and expected heterozygosity $\left(H_{\mathrm{E}}\right)$ ranged from 0.0714 to 0.9231 and from 0.1948 to 0.9237 , respectively. Four loci deviated significantly from Hardy-Weinberg equilibrium. The newly developed microsatellite markers will be beneficial in assessing the genetic diversity, population structure and genetic conservation of $A$. pectinata, and in other relevant research.
\end{abstract}

Key words: Atrina pectinata; Microsatellite loci; Polymorphic 


\section{INTRODUCTION}

The pen shell, Atrina pectinata, belonging to the family Pinnidae, is a kind of eurythermal, euryhaline and large wedge-shaped bivalve, which is widely distributed in the tropical and subtropical regions of the Indian and Western Pacific oceans (Wang et al., 1993). Its adductor muscle and mantle are very important sea foods in Korea, Japan, and China, which is attributed to its good taste and high nutritional value. In China, A. pectinata has high commercial and scientific research value because of the lack of large-scale culture. In the past decades, many problems such as overfishing, disease, deterioration of marine eco-environment have drastically reduced the amount of wild sources. However, to date, the research on the genetic characteristics of the $A$. pectinata population in China has been limited (Ren et al., 2005). Thus, to indentify the status of germplasm resources of Chinese A. pectinata, many further relevant studies on population structure and genetic variation are required.

Microsatellites or simple sequence repeats have been generally accepted as an effective tool to study genetic structure and diversity in animal and plant populations, and they have also been applied in many aquatic research fields. Nowadays, they are used successfully for paternity analysis and kinship studies (Gerloff et al., 1995), DNA fingerprinting and diversity studies (Katti et al., 2001), and genome mapping (Zane et al., 2002) in many organisms, because they have the advantage of abundant polymorphism, co-dominant inheritance, rapid and convenient detection, and so on. Therefore, the development of microsatellite markers can contribute significantly to obtaining more detailed insight into population genetics. Some microsatellite markers from $A$. pectinata have been isolated by Liu (2009) and Chen (2012). However, more effective microsatellite loci will be beneficial to the study of population genetics and construction of a genome map. Here, we present 21 new microsatellite markers in an important bivalve species from the family Pinnidae.

\section{MATERIAL AND METHODS}

Thirty individuals of $A$. pectinata were captured from the Penglai coast, Shandong Province, China. The live organisms were carried to the laboratory, and the adductor muscles of the samples collected were then preserved in alcohol until DNA extraction. Briefly, genomic DNA was extracted from adductor muscle after being digested by proteinase $\mathrm{K} /$ sodium dodecyl sulfate solution. DNA was purified using the standard phenol/chloroform method and precipitation with $3 \mathrm{M} \mathrm{NaCl} /$ ethanol (Aljanabi and Martinez, 1997). DNA was digested with restriction enzyme MspI (Fermentas), and ligated to MspI adaptors (AdapF5'-GATCATGAGT CCTGCT-3'/AdapR5'-CGAGCAGGACTCAGAA-3') using T4 DNA ligase (Fermentas). Subsequently, the fragments ranging from $300 \mathrm{bp}$ to $1000 \mathrm{bp}$ were selected by separation on $1 \%$ agarose gels. The purified fragments were then pre-amplified by polymerase chain reaction (PCR) using AdapF as primer to ensure successful and specific amplification. The PCR products were denatured at $94^{\circ} \mathrm{C}$ for $5 \mathrm{~min}$ and hybridized to biotin-labeled 
(AC) 15 and (AG) 15 probes at $65^{\circ} \mathrm{C}$ for $30 \mathrm{~min}$ in a PCR amplifier. Fragments containing microsatellite repeats were enriched by Streptavidin Magnesphere (Promega) and amplified by AdapF to make it double-stranded. The amplification products were ligated into PMD-18 vector (Takara) at $16^{\circ} \mathrm{C}$ for $30 \mathrm{~min}$, and the ligated fragments were electroporated into Top10 competent Escherichia coli cells (Transgene) and cultured on a LB substrate with ampicillin, IPTG and x-Gal overnight (12-14 h). The recombinant colonies were transferred into $\mathrm{LB}$ culture medium with ampicillin, and shaken for $8 \mathrm{~h}$ at $37^{\circ} \mathrm{C}$. A $1-\mu \mathrm{L}$ aliquot of bacterial suspension was used as template to determine the length of plasmid insert sequence, and the positive clones were then selected for sequencing using the ABIPRISM 3730 Genetic Analyzer (Applied Biosystems). Finally, 109 clones were sequenced, where $93(85.32 \%)$ clones provided available sequences and 66 contained microsatellite loci with at least five uninterrupted repeats. Primer pairs were designed with the highest possible annealing temperature using Primer Premier 5.0.

The primer pairs were tested on 30 individuals collected from Penglai. PCR amplifications were performed in a volume of $25.0 \mu \mathrm{L}$, including $50 \mathrm{ng}$ genomic DNA, $1 \mathrm{X}$ PCR buffer (Transgene), $0.2 \mathrm{mM}$ dNTPs, $0.5 \mu \mathrm{M}$ each primer, and $1.0 \mathrm{U}$ Taq DNA polymerase (Transgene). The thermal profile included an initial denaturation at $94^{\circ} \mathrm{C}$ for $5 \mathrm{~min}$, followed by 30 cycles of denaturation at $94^{\circ} \mathrm{C}$ for $30 \mathrm{~s}$, annealing temperature (Table 1) for $30 \mathrm{~s}$, and extension at $72^{\circ} \mathrm{C}$ for $30 \mathrm{~s}$, followed by a final extension at $72^{\circ} \mathrm{C}$ for $10 \mathrm{~min}$.

The PCR products were resolved on an $8 \%$ denaturing polyacrylamide gel in $1 \mathrm{X}$ TBE buffer containing $8 \mathrm{M}$ urea. After electrophoresis at $450 \mathrm{~V}$ for $3 \mathrm{~h}$ and silver nitrate staining, molecular sizes of the amplified fragments were estimated using a pBR322DNA/ $B s u$ RI Marker. Alleles were counted artificially, and allele size was identified using the ladder as a length reference. Observed $\left(H_{\mathrm{O}}\right)$ and expected $\left(H_{\mathrm{E}}\right)$ heterozygosities and tests for Hardy-Weinberg equilibrium (HWE) and linkage disequilibrium were calculated using the POPGENE software (Version1.31), and PIC was determined with the program PICCALC (Version 0.6). Results were corrected for multiple simultaneous comparisons using Bonferroni correction (Rice, 1989).

\section{RESULTS AND DISCUSSION}

The characteristics of 21 loci are shown in Table 1 and their sequences have been submitted to GenBank. In total, 21 of 66 loci were polymorphic in the population of 30 individuals tested, while the remaining loci were monomorphic or showed poor amplification. Among the 21 detectable loci, the number of alleles observed ranged from 2 to 13 with an average of 6.35. $H_{\mathrm{O}}$ and $H_{\mathrm{E}}$ ranged from 0.0714 to 0.9231 and from 0.1948 to 0.9237 , with an average of 0.46616 and 0.609375 , respectively. Four loci deviated significantly from HWE after Bonferroni correction (adjusted $\mathrm{P}=0.00238$ ), while 17 loci showed no deviation from HWE. No significant genotypic linkage disequilibrium was found between any pair of loci. In this study, we isolated 21 new polymorphic microsatellite markers from A. pectinata, which provide a useful, powerful tool for future research on the assessment of germplasm resources and population conservation of $A$. pectinata. 
B. Wu et al.

10646

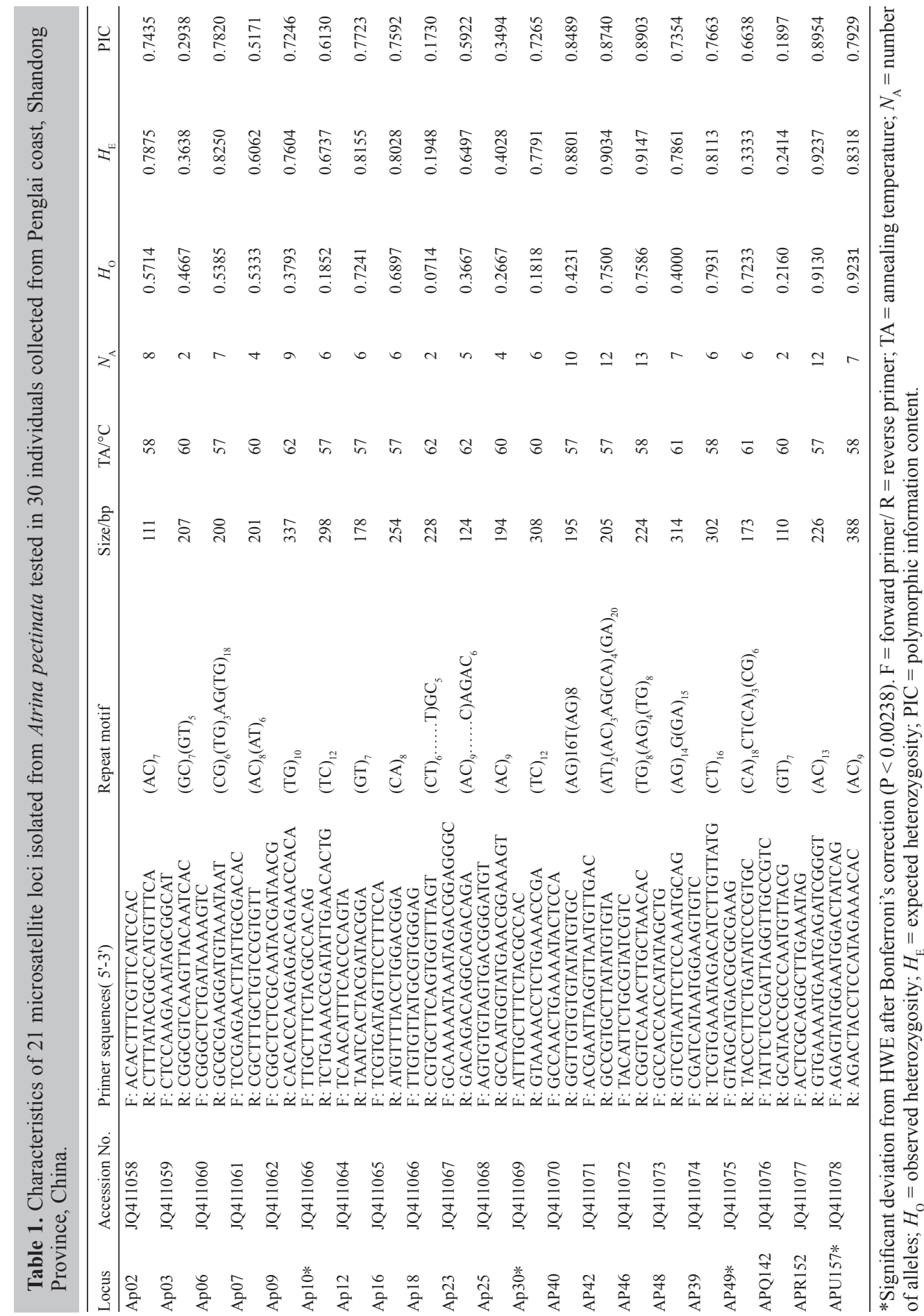

Genetics and Molecular Research 13 (4): 10643-10647 (2014)

CFUNPEC-RP www.funpecrp.com.br 


\section{ACKNOWLEDGMENTS}

Research supported by National Infrastructure of Fishery Germplasm Resources and Strategic Emerging Industry Development Scheme of Qingdao City (\#13-4-1-60-hy) and the Open Fund of Zhejiang Key Laboratory of Aquatic Germplasm Resources (\#KL2013-3). We thank Dr. Manish Raj Pandey for correcting grammar and spelling.

\section{REFERENCES}

Aljanabi SM and Martinez I (1997). Universal and rapid salt-extraction of high quality genomic DNA for PCR-based techniques. Nucleic Acids Res. 25: 4692-4693.

Chen XJ, Li ZB, Chen L, Cao YY, et al. (2012). Isolation and characterization of new microsatellite markers in the pen shell Atrina pectinata (Pinnidae). Genet. Mol. Res. 11: 2884-2887.

Gerloff U, Schlötterer C, Rassmann K, Rambold I, Hohmann G, Fruth B and Tautz D (1995). Amplification of hypervariable simple sequence repeats (microsatellites) from excremental DNA of wild living bonobos (Pan paniscus). Mol. Ecol. 4: 515-518.

Katti MV, Ranjekar PK and Gupta VS (2001). Differential distribution of simple sequence repeats in eukaryotic genome sequences. Mol. Biol. Evol. 18: 1161-1167.

Liu J, Li Q and Kong LF (2009). Isolation and characterization of 13 microsatellite loci in the pen shell Atrina pectinata (Bivalvia: Pinnidae). Conservat. Genet. 10:1369-1371.

Ren JF and Yang AG (2005). Current status of study on pen shell Atrina pectinata and its prospects of application and exploitation. Mar. Fish. Res. 4: 84-87.

Rice WR (1989). Analyzing tables of statistical tests. Evolution 43: 223-225.

Wang RC, Wang ZP and Zhang JZ (1993). The cultivation of marine shellfish. Qingdao Ocean Press, Qingdao.

Zane L, Bargelloni L and Patarnello T (2002). Strategies for microsatellite isolation: a review. Mol. Ecol. 11: 1-16. 